\title{
Enhanced Linear Growth Responses in Hypopituitary Dwarfs Treated with Growth Hormone Plus Androgen versus Growth Hormone Alone
}

\author{
Margaret H. MagGillivray, ${ }^{[21]}$ Marvin Kolotkin, and \\ RiGhard W. MUNSGHaUer \\ Departments of Pediatrics and Radiology, Children's Hospital, State University of New York at Buffalo School of \\ Medicine, Buffalo, New York, USA
}

\section{Extract}

Twelve hypopituitary patients ranging in age from $58 / 12$ to $157 / 12$ years were treated for 12 months with a standardized dose of human growth hormone (HGH), 0.1 or 0.05 $\mathrm{U} / \mathrm{kg}$ three times weekly). From the 7 th to 12 th month inclusive, fluoxymesterone, 2.5 $\mathrm{mg} / \mathrm{m}^{2} / 24 \mathrm{hr}$ per os was given in combination with the growth hormone. From the 12 th to the 18th month, no therapy was given. Heights and weights were recorded every 1 or 2 months. Bone age films were assessed at the onset and again in the 6ih, 12 th, and 18 th month of the study.

In the first 6 months of $\mathrm{HGH}$ therapy, the mean growth rate (centimeters per year $\pm \mathrm{sD})$ was $9.4 \pm 2.3$. During combined treatment with $\mathrm{HGH}$ and fluoxymesterone, the mean growth rate of $13.4 \pm 3$ was significantly greater $(P<0.001)$ than on HGH alone. Post-treatment mean growth rate from the 13th through 18th month, inclusive, was $2.7 \pm 1.2$. Weight gain (kilograms per year $\pm \mathrm{sD}$ ) during combined treatment $(13 \pm 7)$ was significantly greater $(P<0.001)$ than during $\mathrm{HGH}$ administration $(3.4 \pm 2.4)$. Mean advancement in bone maturation (months \pm $\mathrm{SD})$ during HGH $(12 \pm 7.7)$ was not significantly different from the mean gain in bone age during combined treatment $(12 \pm 12)$. In the final 6 months without any therapy, the mean gain in bone age was $8.8 \pm 6.1$. In the 18 months of study, the mean increase in bone age was 33 months, and the mean gain in height age (HA) was 23 months.

Although final evaluation of this treatment program depends upon a longer period of observation, the immediate assessment suggests that the significant improvements in height, weight, and physical appearance were sufficient to compensate for the gains in bone maturation, especially since the patients who entered the study had markedly retarded bone ages.

\section{Speculation}

$\mathrm{HGH}$ and androgens interact synergistically. Androgens stimulate HGH secretion in intact animals. In the hypopituitary state, androgens require the addition of $\mathrm{HGH}$ for optimal promotion of optimal growth and secondary sexual development. 


\section{Introduction}

Long term treatment of hypopituitary patients with $\mathrm{HGH}$ is associated with declining rates of linear growth $[1,2,14]$, which necessitate prolongation of the treatment period, the use of larger doses of HGH, and a delay in the attainment of normal height. Although there is sound experimental proof of synergism between growth hormone and androgen $[13,15,16]$, the combined use of these hormones in children with hypopituitarism has not been generally recommended because of the risk of accelerating bone maturation.

The purpose of this study was to determine if the linear growth responses of patients with hypopituitarism who received HGH might be enhanced by the simultaneous administration of androgen without jeopardizing the attainment of normal adult height defined as height in excess of 5 feet. The effectiveness and safety of the treatment regimens were evaluated by comparison of the rates of linear growth, weight gain, and bone maturation in three consecutive 6month periods during which time the patients received $\mathrm{HGH}$ alone, HGH-androgen combination, and no treatment, respectively.

\section{Methods and Materials}

Twelve hypopituitary patients, nine males and three females, whose ages ranged from $58 / 12$ to $157 / 12$ years entered the study. The three girls had isolated HGH deficiency and exhibited early signs of pubertal development but had not reached their menarche. Of the nine boys, five were prepubertal in age, and their gonadotropin levels could not be meaningfully assessed. The remaining four boys were beyond 14 years of age, manifested no sexual development and had prepubertal levels of gonadotropins in plasma and urine. Two of the boys had organic disease in the pituitary hypothalamic area. One boy had received a serious head injury during infancy and required USP thyroid, $90 \mathrm{mg} / \mathrm{m}^{2} / 24 \mathrm{hr}$. The other boy had a craniopharyngioma which caused deficiencies of adrenocorticotropic, thyroid-stimulating, follicle-stimulating, and luteinizing hormones and vasopressin. In addition to the treatment protocol, he received cortisone, $5 \mathrm{mg} /$ $\mathrm{m}^{2} / 24 \mathrm{hr}$, USP thyroid, $90 \mathrm{mg} / \mathrm{m}^{2} / 24 \mathrm{hr}$, and vasopressin. He was the only child in the group who required cortisone replacement.

The diagnosis of HGH deficiency was confirmed on the basis of abnormal plasma HGH concentrations (peak $<4 \mathrm{ng} / \mathrm{ml}$ ) following stimulation with insulin- induced hypoglycemia and intravenous L-arginine $(0.5$ $\mathrm{g} / \mathrm{kg}$ ) administered separately on 2 separate days. Plasma HGH concentrations were measured by the double antibody radioimmunoassay method [5, 12]. The linear growth rate of all the patients before HGH replacement was less than $4 \mathrm{~cm} /$ year. Among the 12 children, retardation in bone maturation varied from 3 to 8 years below chronologic age.

The treatment protocol consisted of $\mathrm{HGH}, 0.05$ or $0.1 \mathrm{U} / \mathrm{kg}$, administered intramuscularly three times weekly for the first 6 months. Only one child received the $0.05 \mathrm{U} / \mathrm{kg}$ dose. The remaining 11 patients were given $0.1 \mathrm{U} / \mathrm{kg} \mathrm{HGH}$. In the second 6-month period of the study, the standardized dose of HGH was continued in combination with fluoxymesterone, $2.5 \mathrm{mg} / \mathrm{m}^{2} /$ $24 \mathrm{hr}$ per os, administered twice daily. In the third 6month period, $\mathrm{HGH}$ and androgen were discontinued. Throughout the 18 months of study, heights and weights were recorded every 1 or 2 months, and roentgenogram of the left hand and wrist was obtained at 0 , 6,12 , and 18 months. Interpretation of bone age was performed by one radiologist $(R M)$ who was not informed of the treatment schedule. The Gruelich and Pyle [6] standards were used to estimate bone age.

The differences in the rates of linear growth, weight gain and bone maturation during the three consecutive 6-month study periods were analyzed for statistical significance by means of the $t$ test for paired samples.

\section{Results}

Data for the individual patients are given in Table I.

\section{Linear Growth Response}

Figure 1 depicts the linear growth rate in centimeters per year in each study period. During the first 6 months of $\mathrm{HGH}$ treatment, the mean growth rate in centimeters per year $\pm \mathrm{SD}$ was $9.4 \pm 2.3$, and the range was $6-14 \mathrm{~cm} /$ year. Ten children grew at rates exceeding $8 \mathrm{~cm} /$ year, and five grew in excess of $10 \mathrm{~cm} /$ year. No child who entered the study was disqualified because of a poor response to HGH treatment.

During the second 6-month period when HGH and fluoxymesterone were administered simultaneously, the mean growth rate was $13.4 \mathrm{~cm} /$ year $\pm \mathrm{sD} 3.0$ and a range of $8.4-17 \mathrm{~cm} /$ year. Ten children grew at rates exceeding $10 \mathrm{~cm} /$ year. No child showed a decline in growth rate; three showed no improvement, and nine exhibited improved growth rates. The linear growth rates observed during the $\mathrm{HGH}$-androgen treatment 
Table I. Growth responses in hypopituitary dwarfs treated with human growth hormone (HGH) alone versus HGH plus androgen

\begin{tabular}{|c|c|c|c|c|c|c|c|c|c|c|c|c|c|}
\hline \multirow[b]{2}{*}{ Subject } & \multirow[b]{2}{*}{ Sex } & \multirow[b]{2}{*}{$\begin{array}{c}\text { Chronical } \\
\text { age, yr }\end{array}$} & \multirow[b]{2}{*}{$\begin{array}{c}\text { Stage } \\
\text { of sex } \\
\text { devel- } \\
\text { opment }^{1}\end{array}$} & \multirow[b]{2}{*}{$\mathrm{HA},{ }^{2} \mathrm{yr}$} & \multirow[b]{2}{*}{$\mathrm{BA},{ }^{3} \mathrm{yr}$} & \multicolumn{2}{|c|}{ Pretreatment } & \multicolumn{3}{|c|}{ Response to HGH } & \multicolumn{3}{|c|}{ Response to $\mathrm{GH}+$ androgen } \\
\hline & & & & & & $\begin{array}{l}\text { Growth } \\
\text { rate, } \\
\mathrm{cm} / \mathrm{yr}\end{array}$ & $\begin{array}{l}\text { Height, } \\
\text { cm }\end{array}$ & $\begin{array}{c}\text { Growth rate, } \\
\mathrm{cm} / \mathrm{yr}\end{array}$ & $\begin{array}{l}\text { Rate wt } \\
\text { gain, } \mathrm{kg} / \mathrm{yr}\end{array}$ & $\Delta \mathrm{BA}, \mathrm{mo}$ & $\begin{array}{c}\text { Growth } \\
\text { rate } \\
\mathrm{cm} / \mathrm{yr}\end{array}$ & $\Delta \mathrm{BA}, \mathrm{mo}$ & $\begin{array}{l}\text { Rate wt } \\
\text { gain, } \\
\text { kg/yr }\end{array}$ \\
\hline$L P$ & $\mathbf{M}$ & $58 / 12$ & 0 & 2 & $28 / 12$ & 4.0 & 86 & 14 & 5.5 & 0 & 14 & 12 & 10 \\
\hline$M M$ & $\mathrm{M}$ & $76 / 12$ & 0 & $36 / 12$ & $36 / 12$ & 4.0 & 100.6 & 8.3 & 1.8 & 12 & 10.6 & 18 & 6.3 \\
\hline$P G$ & $\mathbf{M}$ & $82 / 12$ & 0 & $42 / 12$ & $33 / 12$ & 4.2 & 106.6 & 12.1 & 5.5 & 12 & 15.9 & 12 & 6.3 \\
\hline$B D$ & $\mathbf{M}$ & $101 / 12$ & 0 & $6^{10 / 12}$ & $46 / 12$ & 3.8 & 120.7 & 11.4 & 1.0 & 6 & 12.1 & 24 & 8.1 \\
\hline$K H$ & $\mathrm{~F}$ & $105 / 12$ & 1 & 6 & $61 / 12$ & 2.6 & 115.6 & 12.1 & 8.1 & 12 & 15.9 & 12 & 9.0 \\
\hline$L S$ & $\mathbf{F}$ & $113 / 12$ & 1 & 6 & $5 \% / 12$ & 3.8 & 116.9 & 9.5 & 1.8 & 24 & 16.5 & 24 & 11.8 \\
\hline$R M$ & $\mathrm{M}$ & $126 / 12$ & 0 & $83 / 12$ & 8 & 2.0 & 128.4 & 8.3 & 1.0 & 12 & 15.9 & 0 & 10 \\
\hline$K B$ & $\mathrm{M}$ & 13 & 0 & $96 / 12$ & 9 & 2.0 & 132 & 10.1 & 3.6 & 18 & 10.7 & 0 & 25.5 \\
\hline$M H$ & $\mathrm{M}$ & $141 / 12$ & 0 & $113 / 12$ & 10 & 1.2 & 143.2 & 7.0 & 1.8 & 12 & 9.5 & 18 & 17.3 \\
\hline$G S$ & $F$ & $149 / 12$ & 1 & 6 & $6^{1} / 12$ & 1.2 & 116.3 & 8.9 & 1.8 & 24 & 14.0 & 14 & 10 \\
\hline$J Z$ & $\mathrm{M}$ & 15 & 0 & $106 / 12$ & 9 & 1.9 & 141.6 & 9.5 & 6.3 & 12 & 17.1 & 36 & 27.3 \\
\hline$T S$ & $\mathrm{M}$ & $157 / 12$ & 0 & $10 \% / 12$ & $126 / 12$ & 1.5 & 142.6 & 6 & 3.6 & 0 & 8.4 & 0 & 14.5 \\
\hline $\begin{array}{c}\text { Mean } \\
\pm \\
\text { so }\end{array}$ & & & & & & $2.7 \pm 1$ & & $9.4 \pm 2.3$ & $3.4 \pm 2.4$ & $12 \pm 7.7$ & $13.4 \pm 3$ & $12 \pm 12$ & $13 \pm 7$ \\
\hline
\end{tabular}

1 According to the system of Tanner.

2 Height age.

${ }^{3}$ Bone age.

period were significantly more $(P<0.001)$ than those documented when only HGH was administered. During the final 6 months, when no treatment was used, the growth rate fell to the pretreatment mean of 2.7 $\mathrm{cm} /$ year $\pm \mathrm{sD}$ 1.2. The growth rates observed in the three study periods were statistically significant from each other $(P<0.001)$.

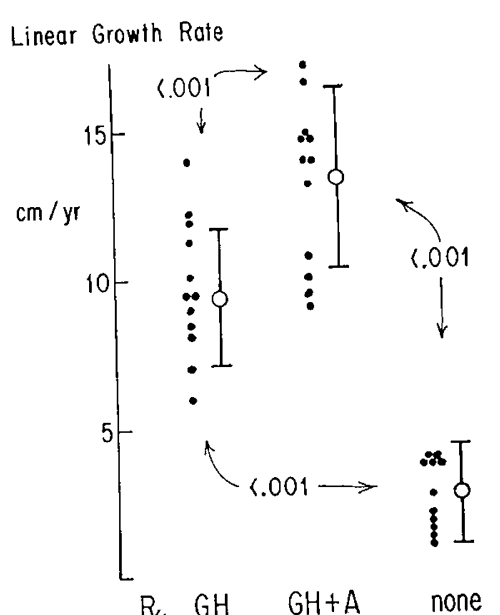

Fig. 1. Comparison of linear growth rates (centimeters per year) of children with hypopituitarism during consecutive treatment (R) periods with human growth hormone alone $(G H)$, human growth hormone plus fluoxymesterone $(G H+A)$ and no therapy (none). Vertical bars represent mean $\pm \mathrm{sD}$.

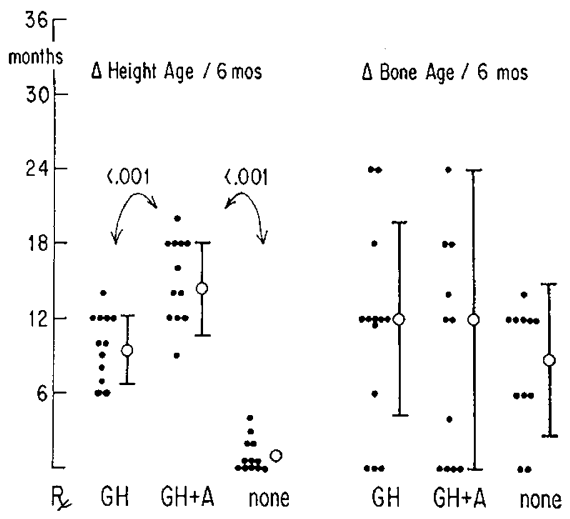

Fig. 2. Increments in height age $(\Delta$ Height Age) and bone age ( $\triangle$ Bone Age) during human growth hormone therapy $(G H)$, combined hormone administration $(G H+A)$, and no therapy (none). Vertical bars represent mean $\pm \mathrm{sD}$.

\section{Increments in Height Age}

The mean increment in height age $(\triangle \mathrm{HA})$ observed during the first 6 months of HGH treatment was 9.5 months \pm sD 2.7. This was significantly less than the gains in HA (14.4 months \pm sD 3.7) recorded during the period of treatment with HGH and androgen $(P$ $<0.001)$. In the last 6 -month period when neither HGH or androgen were administered, the mean increment in HA was 1 month (Fig. 2). 
Weight Gain Rate

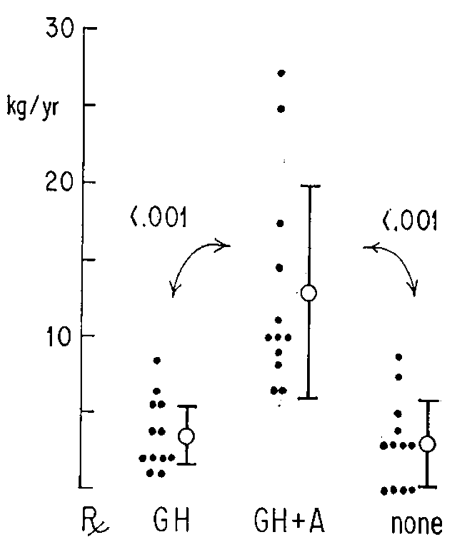

Fig. 3. Comparison of rates of weight gain (kilograms per year) in children with hypopituitarism during therapy $\left(R_{4}\right)$ with human growth hormone alone $(G H)$ versus human growth hormone plus androgen $(G H+A)$ or no therapy (none).

\section{Rate of Weight Gain}

During the $\mathrm{HGH}$ treatment period, the rate of weight gain (kilograms per year $\pm \mathrm{sD}$ ) was $3.4 \pm 2.4$. This was significantly less $(P<0.001)$ than the weight increase of $13 \pm 7.0 \mathrm{~kg} /$ year which resulted from the combined use of HGH and androgen. In the last 6 months when neither HGH or androgens were administered, the weight gains were comparable with those observed during $\mathrm{HGH}$ treatment (Fig. 3). The increment in weight age (WA) during the 6 months of HGH treatment (months $\pm \mathrm{SD}$ ) was $6 \pm 6.8$, which was significantly less $(P<0.001)$ than the WA increment observed during $\mathrm{HGH}$ and androgen treatment $(21 \pm$ 7).

\section{Bone Maturation}

The effect of each treatment period on bone maturation varied greatly. In the first 6 months, the mean advancement in bone maturation (months $\pm \mathrm{sD}$ ) was $12 \pm 7.7$. This was not significantly different from the results observed in the second 6 months of combined HGH-androgen treatment $12 \pm 12$. In the final 6 month study period, the mean increment in bone maturation $(\triangle \mathrm{BA})$ was $8.8 \pm 6.1$ (Fig. 2).

\section{Ratio of Mean $\triangle B A / \triangle H A$}

Figure 4 illustrates the ratio of mean $\Delta \mathrm{BA} / \Delta \mathrm{HA}$ during each study period. This analysis aids in our evaluation of the overall beneficial or harmful effects of the various treatment programs on the rate of bone maturation. The mean actual increment in height age in the 6 months of $\mathrm{HGH}$ treatment was 9 months, and the increment in bone age was 12 months. The ratio $\Delta \mathrm{BA} /$ $\Delta \mathrm{HA}$ was 1.3 , which is slightly unfavorable. In the second 6 months when HGH and androgen were administered, the mean BA (12 months) to HA (14 months) was 0.8 , which is a favorable ratio. In the last 6 months without therapy, the ratio is unfavorable because the mean $\mathrm{HA}$ of 1 month is insignificant whereas the mean $\triangle \mathrm{BA}$ is 8 months. The overall ratio of mean $\triangle \mathrm{BA} / \Delta \mathrm{HA}$ in the 18 months of treatment was 1.4 .

\section{Sexual Development}

Penis growth in all the males was enhanced by the simultaneous administration of $\mathrm{HGH}$ and androgen. In the girls, mild clitoral enlargement occurred but was insufficient to cause concern.

\section{Physical Appearance}

The enhanced weight gain and linear growth of these patients were associated with pronounced improvement in their physical appearance (Fig. 5) and psychologic status.

\section{Discussion}

The data obtained from these clinical studies provide further supportive evidence of a synergistic interaction between HGH and androgen [8, 10, 15, 17]. In 9 of the 12 children with hypopituitarism participating in our study, linear growth was significantly accelerated by the addition of modest doses of fluoxymesterone to an already standardized HGH regimen. Weight gain was also substantially greater during the period of combined hormone administration. Associated with these changes was a pronounced improvement in appearance, more dramatic than we have previously seen in

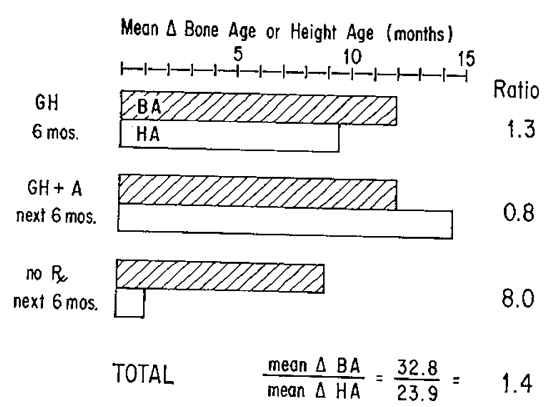

Fig. 4. The ratio of mean increment in bone age $(\triangle B A)$ to mean increment in height age $(\triangle H A)$ is illustrated for each study period consisting of human growth hormone alone $(G H)$, human growth hormone plus androgen $(G H+A)$, or no treatment $\left(\right.$ no $\left.\mathrm{B}_{4}\right)$. The effects of the total study on bone age and height age are summarized. 


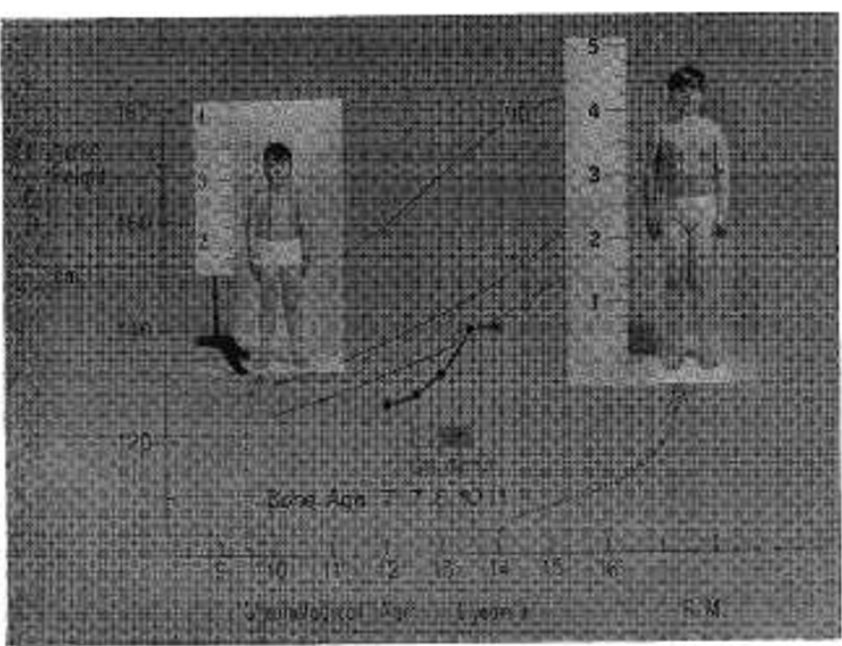

Fig. 5. Enhanced linear growth and weight gain in a patient treated with human growth hormone and androgen.

children with hypopituitarism treated either with $\mathrm{HGH}$ or androgen alone. The enhanced growth responses documented during the concurrent use of $\mathrm{HGH}$ and androgen is in contrast to the reported decline in growth rates seen in hypopituitary patients receiving prolonged, albeit not standardized doses of HGH [1, 2, 14]. Therefore, from these observations, it appears that the improved growth, weight gain, and appearance may be attributed to the synergistic effect of $\mathrm{HGH}$ and androgen.

The interactions between growth hormone and androgens have been extensively examined $[8,10,13,15$, 17]. Studies carried out in intact animals and humans have shown that androgens increase the pituitary content [4] and enhance pituitary secretion of growth hormone [10]. In hypopituitary animals $[13,15]$ and humans $[7,11,17]$, the maximal growth promoting effects of androgens are dependent upon the simultaneous administration of growth hormone. This finding indicates that the peripheral actions of androgens are dependent on an interaction with growth hormone.

The ultimate safety and effectiveness of combined HGH-androgen treatment in hypopituitary dwarfs cannot be fully evaluated in the 18-month study period which comprises this report. The long range effects on bone maturation and possible gonadal function will determine the future role of combined hormonal treatment in hypopituitarism. The mean rate of bone maturation during HGH treatment was similar to the value observed during combined treatment. However, statistical analysis of the effects of the different treatment periods on the rate of bone maturation was invalid because of the marked individual variation in response to treatment. An additional concern is the documented increase in bone maturation during the 6month rest period when neither HGH nor androgen was used. Despite these shortcomings, the overall immediate effect on bone maturation was not clinically unfavorable. Within the 18-month study period, 12 of which consisted of hormone treatment, the mean gain in height age was 23 months, and the mean increase in bone maturation was 33 months. Since all the patients had markedly retarded bone ages, the advancement in bone age was compensated for by the accelerated growth rates and the more mature physical appearance. Eight of the 12 children achieved heights within 2 sD of the mean in the 18 months of study.

Recent studies in animals indicate that methandrostenolone is a potent anabolic agent with weak androgenic properties. Synergism between this anabolic steroid and growth hormone has already been documented in animals [15]. Clinical trials with oxandrolone, a potent anabolic agent with weak androgenic properties, have not shown unfavorable acceleration of bone maturation [3, 9] in short children with intact pituitaries. In view of the evidence which indicates decreasing growth rates in children on long term HGH therapy, it could be argued that HGH combined with oxandrolone may be a more appropriate protocol for the prepubertal child and that the combination of HGH with potent androgens should be reserved for hypopituitary patients of pubertal age.

\section{Summary}

Rates of linear growth and weight gain in hypopituitary patients receiving growth hormone therapy were significantly enhanced by the combined administration of androgen and growth hormone. Within the 18month period of observation, the gains in height, weight, and physical appearance adequately compensated for the increase in bone maturation.

$$
\text { References and Notes }
$$

1. Aceto, T., Jr., Frasier, S. D., Hayles, A. B., Meyer-Bahlburg, H. F. L., Parker, M. L., Munschauer, R. W., and DiChiro, G.: Collaborative study of the effects of human growth hormone in growth hormone deficiency. I. First year of therapy. J. Clin. Endocrinol. Metab., 35: 483 (1972).

2. Aceto, T., JR., Frasier, S. D., Hayles, A. B., AND MeyerBAHLBURG, H. F. X.: Human growth hormone (HGH) in children with GH deficiency: A dose related response; waning effectiveness (submitted to Midwest Pediatric Research Society, November, 1972).

3. Bettmann, H. K., Goldman, H. S., Abramowicz, M., and 
SoBEL, E. H.: Oxandrolone treatment of short stature: Effect on predicted mature height. J. Pediat., 79: 1018 (1971).

4. Birge, C. A., Peake, G. T., Mariz, I. K., and Daughaday, W. H.: Radioimmunoassayable growth hormone in the rat pituitary gland: Effects of age, sex and hormonal state. Endocrinology, 81: 195 (1967).

5. Greenwood, F. C., Hunter, W. M., and Glover, J. S.: The preparation of ${ }^{13 x}$-labeled human growth hormone of high specific radioactivity. Biochem. J., 89: 114 (1963).

6. Gruelich, W. W., and Pyle, S. I.: Radiographic Atlas of Skeletal Development of the Hand and Wrist, Ed. 2 (Stanford University Press, Stanford, California, 1959).

7. Hubble, D., ANo McMillan, E. R.: A study of growth promotion in children. Arch. Dis. Childhood, 37: 518 (1962).

8. Illig, R., AND PRADER, A.: Effect of testosterone on growth hormone secretion in patients with anorchia and delayed puberty. J. Clin. Endocrinol. Metab., 30: 615 (1970).

9. Kaplan, J. G., Moshang, T., JR., Bernstein, R., Parks, J. S., AND Bongrovann, A. M.: Constitutional delay of growth and development: Effects of treatment with androgens. J. Pediat., 82: 38 (1973).

10. Martin, L. G., Clark, J. W., and Connor, T. B.: Growth hormone secretion enhanced by androgens. J. Clin. Endocrinol. Metab., 28: 425 (1968).

11. Prader, A.: The influence of anabolic steroids on growth. Acta Endocrinol. Suppl., 63: 78 (1961).

12. Schalch, D. S., and Parker, M. L.: A sensitive double antibody immunoassay for human growth hormone in plasma. Nature, 203: 1141 (1964).

13. Scow, R. O., AND Hagan, S. N.: Effect of testosterone propionate and growth hormone on growth and chemical composition of muscle and other tissues in hypophysectomized male rats. Endocrinology, 77: 852 (1965).

14. Soyka, L. F., Bode, H. H., Crawford, J. D., and Flynn, F.
J:: Effectiveness of long-term growth hormone therapy for short stature in children with growth hormone deficiency. $J$. Clin. Endocrinol. Metab., 30: 1 (1970).

15. Steinetz, B. G., Giannina, T., Butler, M., and Popick, F.: The role of growth hormone in the anabolic action of methandrostenolone. Endocrinol., 90: 1396 (1972).

16. Widnell, C. C., ANd TATA, J. R.: Additive effects of thyroid hormone, growth hormone and testosterone on deoxyribonucleic acid-dependent ribonucleic acid polymerase in rat liver nuclei. Biochem. J., 98: 621 (1966).

17. Zachman, M., and Prader, A.: Anabolic and androgenic effect of testosterone in sexually immature boys and its dependency on growth hormone. J. Clin. Endocrinol. Metab. 30: 85 (1970).

18. Informed consent was obtained from all patients and/or parents before participation in this study.

19. We are indebted to Dr. T. Aceto, Jr., and Dr. I. Beitins for their support and advice. The authors are most grateful to the Nursing Staff of the Clinical Research Center for their competent technical assistance. The assistance of $\mathrm{Mr}$. R. Oliver and Mrs. M. Link is gratefully acknowledged.

20. The human growth hormone used in this study was provided by the National Pituitary Agency. All clinical diagnostic studies were supported by a grant (RR-628-02) from the General Clinical Research Centers Program of the Division of Research Resources, National Institutes of Health. This research was supported by a grant from the Department of Health, Education, and Welfare, Maternal and Child Health Service (Project 417).

21. Requests for reprints should be addressed to: Margaret $\boldsymbol{H}$. MacGrluivray, M.D., Department of Pediatrics, Children's Hospital, 219 Bryant Street, Buffalo, New York 14222 (USA). 22. Accepted for publication September 28, 1973. 